\title{
EDUCAÇÃO AMBIENTAL: UM ITINERÁRIO PARA A PRESERVAÇÃO DO MEIO AMBIENTE E A QUALIDADE DE VIDA NAS CIDADES.
}

ENVIRONMENTAL EDUCATION: A CHALLENGE FOR THE PRESERVATION OF THE ENVIRONMENT AND THE QUALITY OF LIFE IN THE CITIES.

\author{
Adriana Roseno Monteiro ${ }^{1}$
}

\section{RESUMO}

O presente artigo faz uma discussão acerca da utilização da educação ambiental para a sustentabilidade do meio ambiente e a qualidade de vida da população, tendo em vista, que desvendar a dinâmica ambiental através das múltiplas ações dos atores envolvidos é essencial neste processo. Portanto, os estudos acerca do meio ambiente, em particular, inserem-se de modo especialmente relevante no debate contemporâneo. Por conseguinte, esta pesquisa teve como objetivo principal enfocar a importância da utilização da educação ambiental para a preservação do meio ambiente e para a qualidade de vida nas cidades. Com vistas a alcançar o objetivo proposto, esta pesquisa está alicerçada em um viés qualitativo em que os procedimentos metodológicos adotados foram a revisão bibliográfica e documental, que são essenciais para subsidiar todas as etapas de um trabalho científico. Desse modo, esta pesquisa permitiu percebermos que é prioritária as mudanças de posturas, de hábitos e de costumes em relação aos problemas ambientais e que a educação ambiental se projeta como um mecanismo de grande relevância para a formação de sociedades ecologicamente equilibradas e em harmonia com meio ambiente.

Palavras-chave: Educação Ambiental; Preservação Ambiental; Qualidade de vida. Sustentabilidade. Cidades.

\section{ABSTRACT}

This article discusses the use of environmental education for the sustainability of the environment and the quality of life of the population, in order to unravel the environmental dynamics through the multiple actions of the actors involved, it is essential in this process. Therefore, studies on the environment, in particular, are particularly relevant in the contemporary debate. Therefore, this research had as main objective to focus the importance of the use of environmental education for

\footnotetext{
${ }^{1}$ Graduada em Licenciatura e Bacharelado em Geografia pela Universidade Federal de Roraima (2007). Especialista em Psicopedagogia pela Faculdade Albert Einstein (2010). Especialista em Metodologia do Ensino de História e Geografia pela Faculdade Internacional de Curitiba (2011). Mestrado em Geografia pelo programa de Pós-Graduação em Geografia da Universidade Federal de Roraima. Doutora em Ciências da Educação pela Universidade Politécnica e Artística do Paraguai (2019). Professora da rede pública de ensino do Estado de Roraima. Trabalhos publicados nas áreas de habitação, produção do espaço urbano e educação.E-mail para contato: drycaluz@hotmail.com.br
} 
the preservation of the environment and for the quality of life in the cities. In order to reach the proposed objective, this research is based on a qualitative bias in which methodological procedures adopted were the bibliographical and documentary revision, which are essential to support all stages of a scientific work. Thus, this research allowed us to perceive that priority is given to changing postures, habits and customs in relation to environmental problems and that environmental education is projected as a mechanism of great relevance for the formation of ecologically balanced societies and in harmony with the environment.

Keywords: Environmental Education; Environmental Preservation; Quality of life. Sustainability. Cities.

\section{INTRODUÇÃO}

A degradação do meio ambiente vem aumentando intensivamente, tendo ao mesmo tempo, seu ritmo acelerado em decorrência da sua apropriação cada vez maior pelo homem, a fim de suprir suas necessidades imediatas ou não. Os danos causados pelas ações antrópicas impõem uma necessidade de se buscar formas mais adequadas de desenvolvimento que respeitem as fragilidades e limitações ambientais.

A educação ambiental torna-se uma prática necessária, inclusive nos meios escolares, sendo um instrumento imprescindível para a consolidação de novos modelos de desenvolvimento sustentável, visando uma conduta mais sensata dos indivíduos em defesa do meio ambiente, atuando como multiplicadores junto as suas comunidades, pois ações individuais e coletivas contribuem para a conservação e preservação do meio ambiente e melhoria da qualidade de vida nas cidades.

Dessa maneira, a educação ambiental tem uma proposta transformadora à medida que leva o indivíduo a construir valores e atitudes intimamente associadas às experiências cotidianas, desenvolvendo uma consciência e um compromisso que possibilitem a mudanças, desde as pequenas atitudes individuais até uma participação pluralista.

Nesta perspectiva, este trabalho foi desenvolvido com a certeza de que é necessário descortinar as perspectivas e delinear os entraves que compõem a questão ambiental, tendo assim como objetivo principal enfocar a importância da utilização da educação ambiental para a preservação do meio ambiente e para a qualidade de vida nas cidades.

Esta pesquisa adotou como procedimentos metodológicos: a pesquisa bibliográfica efetuada por meio de livros, artigos, dissertações e teses e a pesquisa documental - realizada 
através de leis, decretos, manuais, e outros documentos que se fazem necessários para a realização de um estudo científico estruturado em bases teóricas sólidas.

Convém ressaltar que a análise de todos estes dados foi feita através de um viés crítico e normativo da ciência, assim este estudo não está fixado somente em concepções descritivas, mais também contém um teor substancialmente crítico.

Tomando como referência o objetivo elencado juntamente com os procedimentos metodológicos, este artigo além da presente introdução e das considerações finais, está estruturado em três recortes basilares, nos quais foram desenvolvidas com base em um estudo exploratório de natureza qualitativa e por meio de uma revisão da literatura:

Na primeira seção, intitulada "A sustentabilidade ambiental", evidencia a eminente necessidade práticas sustentáveis diante do avançado processo de degradação da natureza para a manutenção do equilíbrio ambiental que alie desenvolvimento econômico, preservação ambiental e qualidade de vida das populações nas cidades.

Na segunda seção, nomeada "Educação ambiental: conceito e fundamentos sóciohistóricos", faz uma discussão acerca do conceito de educação ambiental bem como os seus fundamentos sócio-históricos pautada na convicção de que é necessário desembaraçar os entraves e conhecer os diversos fatores que compõem a questão ambiental, a partir da capacidade de aglutinar visões e expectativas em torno dessa temática.

Na terceira seção, denominada "Educação ambiental: preservação do meio ambiente e qualidade de vida nas cidades", apontará a importância da educação ambiental para a preservação do meio ambiente tendo em vista a necessidade de se repensar o modelo de desenvolvimento atual para alcançarmos um ambiente sustentável para as presentes e futuras gerações assim como qualidade de vida meio urbano.

Por fim, as últimas considerações são trazidas à guisa de conclusão, por meio da identificação dos principais temas abordados no artigo com intuito de constituir um aporte conceitual estruturado em bases teóricas sólidas sobre o tema, que poderá subsidiar futuros projetos de melhorias na área ambiental e urbana e contribuir para o reconhecimento da necessidade de se repensar a questão ambiental tanto para a preservação do meio ambiente como para a melhoria da qualidade de vida das populações nas cidades. 


\section{EDUCAÇÃO AMBIENTAL: CONCEITO E FUNDAMENTOS SÓCIO-HISTÓRICOS}

A questão ambiental emerge como um problema significativo a nível mundial em torno dos anos 70 , expressando um conjunto de contradições entre o modelo dominante de desenvolvimento econômico-industrial e a realidade socioambiental. Essas contradições, engendradas pelo desenvolvimento técnico-científico e pela exploração econômica, se revelaram na degradação dos ecossistemas e na qualidade de vida das populações, levantando, inclusive, ameaças à continuidade da vida a longo prazo nas cidades.

Os reflexos deste processo podem ser observados nas múltiplas faces das crises sociais e ambientais e tem gerado reações sociais diversas, em escala mundial, despertando a formação de uma consciência em torno da problemática ambiental, tanto a nível nacional como internacional.

Embora de formas diferenciadas, essa consciência ecológica cresceu e, gradualmente, foi se materializando no seio da opinião pública, nos movimentos sociais, na educação, nos meios científicos, nas agências e políticas públicas, nos veículos de comunicação social, nas organizações não-governamentais, entre outros.

Viola e Leis ${ }^{2}$ analisam, com clareza, a evolução do movimento e consciência ambientalista mundial e brasileiro. Constatam que o movimento no Brasil, iniciado a partir de minorias de cientistas e militantes ambientalistas, organizados em torno de denúncias de agressões e da defesa dos ecossistemas, foi gradualmente se ampliando, conquistando novos espaços, até ganhar a feição multissetorial que hoje o caracteriza. Do ponto de vista das preocupações e temáticas orientadoras, expandiu-se o foco de atenção, para incluir questões como a ecologia política, a questão demográfica, a relação entre desigualdade social e degradação ambiental, a questão ética e a busca de um novo modelo de desenvolvimento.

O impacto da ação humana sobre o meio ambiente varia historicamente de acordo com o modo de produção, a estrutura de classes, o aparato tecnológico, o crescimento demográfico, a expansão das cidades e o universo cultural de cada sociedade.

A temática ambiental vem passando assim por diversos momentos ao longo da história, com avanços e retrocessos, com o desdobramento de diversos acontecimentos, a produção de

\footnotetext{
${ }^{2}$ VIOLA E LEIS, 1995.
} 
documentos oficiais e legislações específicas voltadas para a preservação e conservação do meio ambiente, tanto em escala nacional como supranacional.

No início desse século, são várias as conferências e seminários sobre a temática ambiental em diversas partes do mundo. O rápido crescimento demográfico, a expansão desordenada do espaço urbano, a exploração excessiva dos recursos naturais, a degradação do meio ambiente, a pobreza persistente de grande parte da humanidade, a injustiça, a violência que padecem ainda milhões de pessoas exigem ações corretivas mais intensas.

Para Dias $^{3}$ o ser humano deve modificar o quadro de insustentabilidade existente no planeta. Para tanto, será necessário descobrir um novo estilo de vida baseado em uma ética global, resgatar e criar novos valores e repensar e modificar os seus hábitos de consumo e viabilizar o desenvolvimento sustentável. Sendo assim, a educação ambiental é o instrumento principal para processar essas transformações.

Portanto, as questões ambientais são cada vez mais discutidas em diversos setores da sociedade, a mídia com a intensificação de notícias sobre catástrofes ambientais e mais recentemente sobre o aquecimento global têm chamado atenção de muitos.

A educação ambiental nesse século deverá então responder ao desafio ambiental contemporâneo por meio da conscientização da importância de mudanças de valores e comportamentos da sociedade atual e da necessidade de sua urgente transformação para assegurar a própria sobrevivência da espécie humana e da vida em todos seus aspectos.

A Lei № $9.795^{4}$ dispõe sobre a Política Nacional de Educação Ambiental, no capítulo I e Art. $1^{\circ}$ expõe que:

Art. 10 - Entendem-se por educação ambiental os processos por meio dos quais o indivíduo e a coletividade constroem valores sociais, conhecimentos, habilidades, atitudes e competências voltadas para a conservação do meio ambiente, bem de uso comum do povo, essencial à sadia qualidade de vida e sua sustentabilidade.

Portanto, a educação ambiental é um processo que visa desenvolver o senso crítico e raciocínio lógico, inserindo o homem no seu real papel de integrante e dependente do meio ambiente, intentando uma modificação de valores e atitudes no que se refere às questões

\footnotetext{
${ }^{3}$ DIAS, 2002.

${ }^{4}$ Lei № 9.795, de 27 de abril de 1999.
} 
ambientais, sociais, culturais, econômicas, políticas e éticas, o que levaria à melhoria da qualidade de vida nas cidades o que está diretamente ligada ao tipo de convivência que o homem mantêm com a natureza.

É necessário a aquisição de novos conhecimentos acerca dos problemas ambientais e de suas consequências para a vida nas cidades, a fim de despertar no indivíduo e na coletividade uma consciência ambiental, com o desenvolvimento de novos valores, ações e habilidades voltadas para a sustentabilidade dos recursos naturais. Dias 5 salienta que "o comportamento das pessoas em relação ao seu ambiente natural e artificial é a expressão clara de valores e atitudes, compreensão e habilidades".

A educação ambiental é a incorporação de critérios socioambientais, ecológicos, éticos e estéticos, nos objetivos didáticos da educação, pretendendo-se construir novas formas de pensar incluindo a compreensão da complexidade e das emergências e inter-relações entre os diversos subsistemas que compõem a realidade. ${ }^{6}$

A Lei № $9.795^{7}$ que dispõe sobre a educação ambiental, no capítulo I da Educação Ambiental e Art. $5^{\circ}$ define os objetivos da educação ambiental no Brasil:

Art. 5o - São objetivos fundamentais da educação ambiental:

I - o desenvolvimento de uma compreensão integrada do meio ambiente com suas múltiplas e complexas relações, envolvendo aspectos ecológicos, psicológicos, legais, políticos, sociais, econômicos, científicos, culturais e éticos;

II - a garantia de democratização das informações ambientais;

III - o estímulo e o fortalecimento de uma consciência crítica sobre a problemática ambiental e social;

IV - o incentivo à participação individual e coletiva, permanente e responsável, na preservação do equilíbrio do meio ambiente, entendendo-se a defesa da qualidade ambiental como um valor inseparável do exercício da cidadania;

V - o estímulo à cooperação entre as diversas regiões do País, em níveis micro e macrorregionais, com vistas à construção de uma sociedade ambientalmente equilibrada, fundada nos princípios da liberdade, igualdade, solidariedade, democracia, justiça social, responsabilidade e sustentabilidade;

VI - o fomento e o fortalecimento da integração com a ciência e a tecnologia;

\footnotetext{
${ }^{5}$ DIAS, 2004, p. 215.

${ }^{6}$ MEDINA; SANTOS, 2009.

${ }^{7}$ Lei № 9.795, de 27 de abril de 1999.
} 
VII - o fortalecimento da cidadania, autodeterminação dos povos e solidariedade como fundamentos para o futuro da humanidade.

Portanto, são objetivos fundamentais da educação ambiental uma consciência crítica frente às questões ambientais e sociais, a aquisição de conhecimentos sobre esta temática, bem como incentivar mudanças de hábitos, em prol da preservação do meio ambiente.

É necessário empreender a construção de valores e habilidades que estimulem a participação de cidadãos no enfrentamento dos problemas ambientais, com o objetivo final de melhoria da qualidade de vida nas cidades e de formação de sociedades sustentáveis que se revelam como perspectivas contemporâneas. Esses três componentes - conhecimentos, habilidades e atitudes influenciam diretamente as práticas sociais e constituem bases da educação ambiental.

O desenvolvimento de hábitos, atitudes e conhecimentos que levem a uma mudança de posicionamento dos cidadãos no ambiente natural é propósito da educação ambiental. Proteção, preservação, conservação, recuperação ambiental têm sido defendidas como forma de amenizar danos ou desequilíbrios provocados no meio ambiente. Tais desequilíbrios ou alterações vêm prejudicando seres vivos, e em alguns casos, impedindo processos vitais. ${ }^{8}$

Segundo Santos ${ }^{9}$ um objetivo fundamental da educação ambiental é permitir que os indivíduos se engajem no enfrentamento e na resolução das problemáticas ambientais que lhes atingem mais diretamente, sempre tendo como ponto central à compreensão da natureza complexa do meio ambiente natural e do meio ambiente criado pelo homem, resultante da integração de seus aspectos biológicos, físicos, sociais, econômicos e culturais.

Dessa maneira, a educação ambiental deve propiciar a formação de um cidadão consciente, que possa entender os processos interativos no meio ambiente e sentir-se como parte dele, sendo capaz de agir em seu espaço de vida de modo a garantir a sustentabilidade ambiental, como veremos na seção a seguir.

\section{A SUSTENTABILIDADE AMBIENTAL}

\footnotetext{
${ }^{8}$ GIESTE, 2002.

${ }^{9}$ SANTOS, 2005.
} 
A sociedade atual tem passado por diversas transformações com o incremento da urbanização e a consolidação de um sistema capitalista em que a busca pelo lucro é apenas uma de suas características.

À medida que o ser humano foi se distanciando da natureza e passou a encará-la como uma gama de recursos disponíveis a serem transformados em bens consumíveis, começaram a surgir os problemas socioambientais ameaçando a sobrevivência do nosso planeta. A educação ambiental surgiu então como uma necessidade de mudança na forma de encarar o papel do ser humano no mundo. ${ }^{10}$

Mediante uma sociedade cada vez mais consumista as interferências no meio ambiente são cada vez mais acirradas. Em consequência disso, aumenta-se mais os níveis de degradação ambiental, pois "a evolução social e a evolução cultural são mais rápidas do que a evolução biológica. Portanto, a evolução biológica não pode acompanhar os desequilíbrios ambientais produzidos pela evolução sociocultural" ${ }^{11}$

Para Valdemeri ${ }^{12}$ desde o princípio dos tempos o homem estabeleceu o uso do espaço territorial para satisfazer suas necessidades, fazendo uso dos recursos naturais renováveis e nãorenováveis para satisfazer sua própria sobrevivência, sem perceber, ao longo do tempo passou a adotar um comportamento predatório em relação ao ambiente em que vive, transformando o ambiente natural e saudável que herdou, em um espaço desequilibrado e em completa desarmonia entre seus habitantes.

Manter a qualidade de vida nas cidades e regiões torna-se cada vez mais difícil, necessitando-se que os problemas ambientais sejam minimizados, sendo preciso então garantir padrões ambientais adequados e estimular uma crescente consciência ambiental, centrada no exercício da cidadania e na reformulação de valores éticos e morais, individuais e coletivos, numa perspectiva orientada para o desenvolvimento sustentável.

O desenvolvimento sustentável é a utilização dos recursos naturais de forma equilibrada pela sociedade atual e que garanta a sua preservação para atender tanto a presente como as futuras gerações. Mediante a isto, este torna-se essencial para a manutenção do equilíbrio ambiental.

\footnotetext{
${ }^{10}$ DUVOISIN, 2002.

${ }^{11}$ DIAS, 2004, p. 214.

12 VALDEMERI, 2004.
} 
Para Hermoso ${ }^{13}$ o conceito de desenvolvimento sustentável implica que a exploração dos recursos naturais deve ser feita em condições tais que as futuras gerações possam utiliza-los e beneficiar-se de um processo contínuo e equilibrado, no qual a redução das desigualdades econômicas e sociais e a diminuição da pobreza sejam metas fundamentais.

A sustentabilidade ambiental deve estar pautada em princípios ecológicos, com o manejo adequado dos recursos naturais, a conservação da biodiversidade e também guiada por princípios econômicos e sociais que garantam o atendimento das necessidades básicas da sociedade, a distribuição equitativa da riqueza gerada, uma convivência mais harmoniosa do homem no espaço urbano e com isso a minimização dos impactos ambientais.

De acordo com Warren ${ }^{14}$ o desenvolvimento sustentável deve ser concebido enquanto fenômeno multidimensional. Como uma contra força à degradação econômica, política, cultural e ambiental, contra a exploração, a exclusão social e a discriminação, por um lado, e como uma força que respeite e promova os direitos humanos tanto (civil, socioeconômico, cultural e ambiental), a integração não apenas no campo da produção, mas também da cooperação solidária, a cidadania através do reconhecimento e da participação e a segurança em relação a todas as formas de violência.

A sustentabilidade ambiental é uma nova forma do homem se relacionar com o meio ambiente que alia o desenvolvimento econômico e social e a manutenção dos recursos naturais garantindo assim a qualidade de vida nas cidades. Lerípio ${ }^{15}$ contribui para essa reflexão quando afirma que a relação entre meio ambiente e desenvolvimento deve deixar de ser conflitante para tornar-se uma relação de parceria, na qual o ponto chave da questão passa a ser a necessidade de uma convivência pacífica entre a boa qualidade do meio ambiente e o desenvolvimento econômico.

Para Barros ${ }^{16}$ o desenvolvimento sustentado não é centrado exclusivamente na produção, a chave está nos indivíduos, na participação, na organização, na educação, no fortalecimento cultural e na distribuição equitativa de rendas, haja vista, que ideias de sociedade sustentáveis baseiam-se na necessidade de se pensar em diversidade, com opções econômicas e tecnológicas diferenciadas, voltadas para o desenvolvimento harmonioso das pessoas e de suas relações com o conjunto do mundo natural, um processo que permita buscar a sustentabilidade ambiental, social e política nas cidades.

\footnotetext{
${ }^{13}$ HERMOSO, 2005.

${ }^{14}$ WARREN, 2007.

${ }^{15}$ LERÍPIO, 2001.

${ }^{16}$ BARROS, 2002.
} 
Diante deste cenário a educação ambiental se desponta como um instrumento de grande relevância para alcançarmos uma sociedade sustentável. Pois para a sua efetivação é preciso que os indivíduos entendam a sua inter-relação com o meio ambiente e as implicações de suas ações.

Assim, a conscientização deve ser precursora nesse processo considerando a importância das atitudes individuais, assim, como as coletivas. Devendo-se buscar um convívio harmonioso entre o homem e os recursos ambientais como uma estratégia de sobrevivência.

O processo de educação ambiental requer para o sucesso em suas atividades que a sociedade seja tolerante, onde forças novas podem emergir fundando-se sobre uma análise crítica, uma vez que contestam o paradigma vigente. Encorajam-se no seu empenho para romper fronteiras e barreiras que se opõem à perspectiva da sociedade sustentável. ${ }^{17}$

É preciso garantir padrões ambientais adequados e estimular uma crescente consciência ambiental, centrada no exercício da cidadania e na reformulação de valores éticos e morais, individuais e coletivos, numa perspectiva orientada para o desenvolvimento sustentável. Sendo que a educação ambiental se constitui em um dos mecanismos fundamentais nesse processo. A figura 01 mostra os mecanismos essenciais para alcançarmos a sustentabilidade nas cidades.

Figura 01 - Sustentabilidade Ambiental

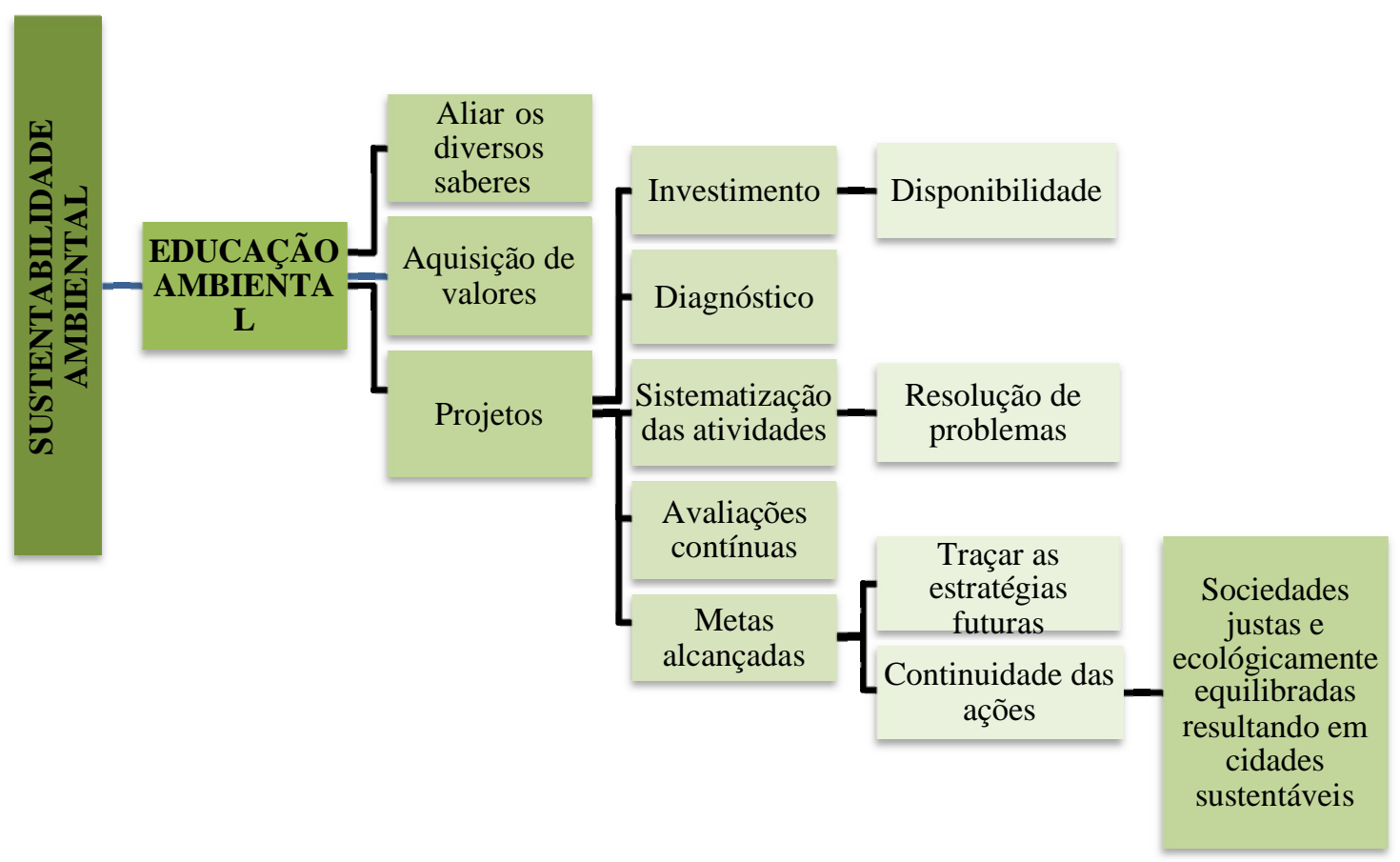

Organização e elaboração pela autora.

\footnotetext{
${ }^{17}$ RUSCHEINSKY, 2007.
} 
Estimular a formação de sociedades socialmente justas e ecologicamente equilibradas que conservem entre si a relação de interdependência e diversidade, requer responsabilidade individual e coletiva em nível local, nacional e global e depende da compreensão da natureza sistêmica das crises que ameaçam o futuro do planeta como o aumento da pobreza, da degradação humana e ambiental e da violência, que podem ser identificadas no modelo de civilização dominante, que se baseia em superprodução e superconsumo para uns e em subconsumo e falta de condições da grande maioria. ${ }^{18}$

Para que o desenvolvimento sustentável se efetive deve está centrado não somente na produção, mas também nos atores sociais, propiciando as condições necessárias para os indivíduos se posicionarem e agirem em busca de caminhos mais justos e solidários que transponha os desafios de construção, ocupação e transformação do meio natural e cultural e que vislumbre cidades mais sustentáveis.

Somente uma conduta que contemple a responsabilidade individual e plural será capaz de gerar uma nova trajetória nas formas de desenvolvimento que sejam adequadas a sustentabilidade do meio ambiente. Por intermédio da educação ambiental é possível dar condições aos indivíduos de se posicionarem e agirem em busca de caminhos mais justos e solidários frente aos desafios do processo ocupação e transformação das cidades e garantir uma melhor qualidade de vida para as populações.

\section{EDUCAÇÃO AMBIENTAL: PRESERVAÇÃO DO MEIO AMBIENTE E QUALIDADE DE VIDA}

Mais do que nunca, justifica-se a necessidade de se buscar a conservação e a preservação da biodiversidade sendo significativa à proteção de áreas que venham a abranger os diversos tipos de ecossistemas além do uso racional da fauna e flora, já que "a população humana, mais do que qualquer outra, tem causado danos ao ambiente e, portanto, deve ser responsável por ações corretivas e preventivas". ${ }^{19}$

Os problemas ambientais trazem consequências sutis para a maioria da população. 0 aquecimento global, a falta de espaço para a deposição dos resíduos, a poluição do ar, são fatores que passam despercebidos na maioria das cidades. E quando são agravantes em alguma cidade, como por exemplo a poluição do ar, toma-se medidas mitigadoras do problema, permitindo aos poucos a convivência com este problema mesmo com perdas à qualidade de vida. Porém, para

\footnotetext{
${ }^{18}$ BARROS, 2002.

${ }^{19}$ DIAS, 2004, p. 215.
} 
quem vive em cidades em que a qualidade ambiental é regular até ótima, pode-se dizer que a preocupação com a questão ambiental torna-se um assunto exclusivo de ambientalistas. Portanto, pensar em resolver os problemas que perturbam o equilíbrio ambiental local é fato comum, mas propor e agir para que haja uma solução para estes problemas é um passo maior, que pode depender das necessidades das comunidades locais ou mesmo de ações individuais que busquem a mobilização social. ${ }^{20}$

Frente aos inúmeros desafios do futuro, a educação ambiental surge como imprescindível à humanidade, como uma via que conduz a um desenvolvimento humano mais harmonioso, devendo se traçar estratégias capazes de envolver os atores e promover dinâmicas de mudanças capazes de modificar as práticas de uso e preservação do meio ambiente.

Neste contexto, a educação ambiental é primordial para alcançarmos uma relação mais harmoniosa entre homem e o meio ambiente, pois ela tem um papel fundamental na formação de indivíduos mais conscientes e comprometidos com meio em que vivem. Ela é um componente substancial de qualquer política de desenvolvimento e de uma eficaz instrumentalização da cidadania.

Para Grüm ${ }^{21}$ (1996) a degradação ambiental tem alcançado níveis jamais vistos e que vivemos hoje em uma crise ambiental sem precedentes. Sendo necessária uma reorientação da atuação humana em sua relação com o meio ambiente, surgindo em tal contexto, a educação ambiental, não só como necessidade, mas também como esperança.

A educação ambiental é uma resposta a muitos dos problemas verificados no dia-a-dia das cidades, pois a mudança de postura com a adoção de novos comportamentos por parte da população poderá levar a resultados duradouros, os quais permitirão evitar os grandes problemas que afetam o meio ambiente. Santos ${ }^{22}$ esclarece que a educação ambiental é um importante instrumento de sensibilização em busca da consciência ambiental da população, podendo levar a mudanças de atitude e à realização de ações em prol do ambiente, visando à preservação ou a conservação e buscando a melhoria da qualidade ambiental nos espaços urbanos.

Para a realização do direito a um ambiente ecologicamente equilibrado, além de cada indivíduo fazer a sua parte no sentido de contribuir para a proteção e qualidade do meio ambiente, é necessário também despertar nos indivíduos o desejo de participar na construção de sua

\footnotetext{
${ }^{20}$ SANTOS, 2005.

${ }^{21}$ GRÜM,1996.

22 SANTOS, 2005
} 
cidadania, levando os indivíduos e os grupos a perceberem a relevância de ação imediata para o encaminhamento das demandas relativas ao meio ambiente. ${ }^{23}$

É preciso que o homem se conscientize dos problemas ambientais existentes e que é necessário criar oportunidades de vivência que permitam evidenciar tomadas de atitudes, denotando valores e responsabilidades perante os efeitos negativos de suas ações ao meio ambiente.

Segundo Carvalho ${ }^{24}$ um processo de educação ambiental bem conduzido deve ter como grande objetivo, o auxílio na formação de uma consciência crítica nos indivíduos, assim sendo, serão capazes de situarem-se no contexto geral do mundo em que vivem, e estarem mais recíprocos a participarem das soluções aos problemas ambientais.

Em um processo participativo o indivíduo pode assumir um papel de elemento central, atuando ativamente no diagnóstico dos problemas locais e na busca de soluções, sendo preparado como agente transformador através do desenvolvimento de habilidades e formação de atitudes, através de uma conduta ética e condizentes ao exercício da cidadania.

A educação ambiental deve fortalecer a atuação das populações, dando-lhes instrumentos para planejar, gerenciar e implementar suas próprias alternativas às políticas sociais vigentes, além de resgatar e criar soluções para melhoria das condições de vida nas cidades através do desenvolvimento de relações mais solidárias e efetivas.

Por meio de uma visão reflexiva e crítica da realidade e à formação de consciências individuais e coletivas engendradas pela educação ambiental é possível compreender as múltiplas transformações que ocorrem no meio em que se vive, entender a interação do homem com a natureza e como conviver em harmonia com ela buscando soluções possíveis para as problemáticas ambientais.

O indivíduo tem que saber e sentir-se como parte do meio ambiente e desenvolver a capacidade para identificar os danos causados a ele e a sua responsabilidade neste processo, bem como perceber a necessidade de cuidar melhor dele e buscar o equilíbrio com a natureza, pois somente assim será possível termos "o direito ao meio ambiente ecologicamente equilibrado

\footnotetext{
${ }^{23}$ RUSCHEINSKY; VARGAS, 2002.

${ }^{24}$ CARVALHO, 2001.
} 
essencial à qualidade de vida que impõe ao Poder Público e à coletividade o dever de preservá-lo para as presentes e futuras gerações" ${ }^{25}$

Dessa maneira, a educação ambiental é importante para auxiliar na sensibilização das pessoas sobre o meio ambiente, como ele funciona, como dependem dele e como o afetam direta e indiretamente, levando-as a participar ativamente de sua defesa e melhoria. Gonçalves e Lima ${ }^{26}$ asseguram que cabe, à educação ambiental, promover a sensibilização e a conscientização para a mudança de comportamento do sujeito em sua relação cotidiana e individualizada com o meio ambiente e com os recursos naturais, objetivando a formação de hábitos ambientalmente responsáveis no meio social.

Portanto, é salutar destacarmos a necessidade da participação da comunidade e também do Poder Público como agentes construtores de um meio ambiente saudável, objetivando a melhoria da qualidade de vida da população e a sustentabilidade ambiental nas cidades.

A implementação de uma educação ambiental eficiente deve estar voltada para os problemas atuais e urgentes, que perpasse desde ações locais até abordagem de forma global e a busca de soluções. Tendo assim como papel fundamental a formação de cidadãos comprometidos com o meio em que vive, bem como definir os instrumentos para planejar e fiscalizar além de suas próprias práticas às políticas sociais vigentes.

É impreterível que cada indivíduo busque inteirar-se das discussões mundiais e locais, estando sempre propenso e aberto a novas experiências cognitivas. É preciso se desprender das amarras das velhas práticas e expandir os métodos de aprendizagens com o desenvolvimento de iniciativas que busquem possibilitar vivências, reflexões, aprendizagens, construções de conhecimentos e o fortalecimento do trabalho coletivo. E isto somente é possível a partir do planejamento e ações perante os problemas e temas de cunho socioambiental da realidade local do meio urbano.

Lima e Mourão ${ }^{27}$ atestam que o mundo atual exige por parte do homem uma postura diferenciada em relação à questão ambiental. A proposta educativa, situada numa dimensão de inserção social crítica e transformadora, tem como horizonte a formação de sujeitos emancipados. Projetando essa perspectiva para a educação ambiental, verifica-se que a mesma tem como

\footnotetext{
${ }^{25}$ BARROS, 2002, p. 49.

${ }^{26}$ GONÇALVES; LIMA, 2004.

${ }^{27}$ LIMA; MOURÃO, 2007.
} 
compromisso a formação de sujeitos ecológicos, os quais venham reafirmar suas responsabilidades com o meio em que vive.

A educação ambiental deve ser uma prática social, em que cada indivíduo deve fazer a sua parte para conviver em harmonia com o meio ambiente, pois atitudes e comportamentos mais conscientes por parte do homem são eficazes medidas de preservação ambiental e consequentemente de melhoria na qualidade de vida das populações nas cidades.

As mudanças devem começar dentro de cada um de nós. Após uma revisão de nossos hábitos, tendências e necessidades, podem de certa forma, através da adoção de novos comportamentos, dá a nossa contribuição para a diminuição da degradação ambiental e para a defesa e promoção da qualidade de vida. ${ }^{28}$

As atividades de educação ambiental não podem ser pontuais, isoladas e esporádicas, haja vista, que a educação ambiental requer a sistematização das atividades e continuidade de suas ações, com avaliações contínuas de seus resultados a fim de traçar as estratégias futuras com êxito. Portanto, é necessário desenvolver iniciativas mais consolidadas que colaborem com a construção de cidades sustentáveis. A figura 02 faz uma melhor sistematização das etapas da educação ambiental.

Figura 02 - Equacionalização da educação ambiental

\footnotetext{
${ }^{28}$ CURRIE, 2005.
} 


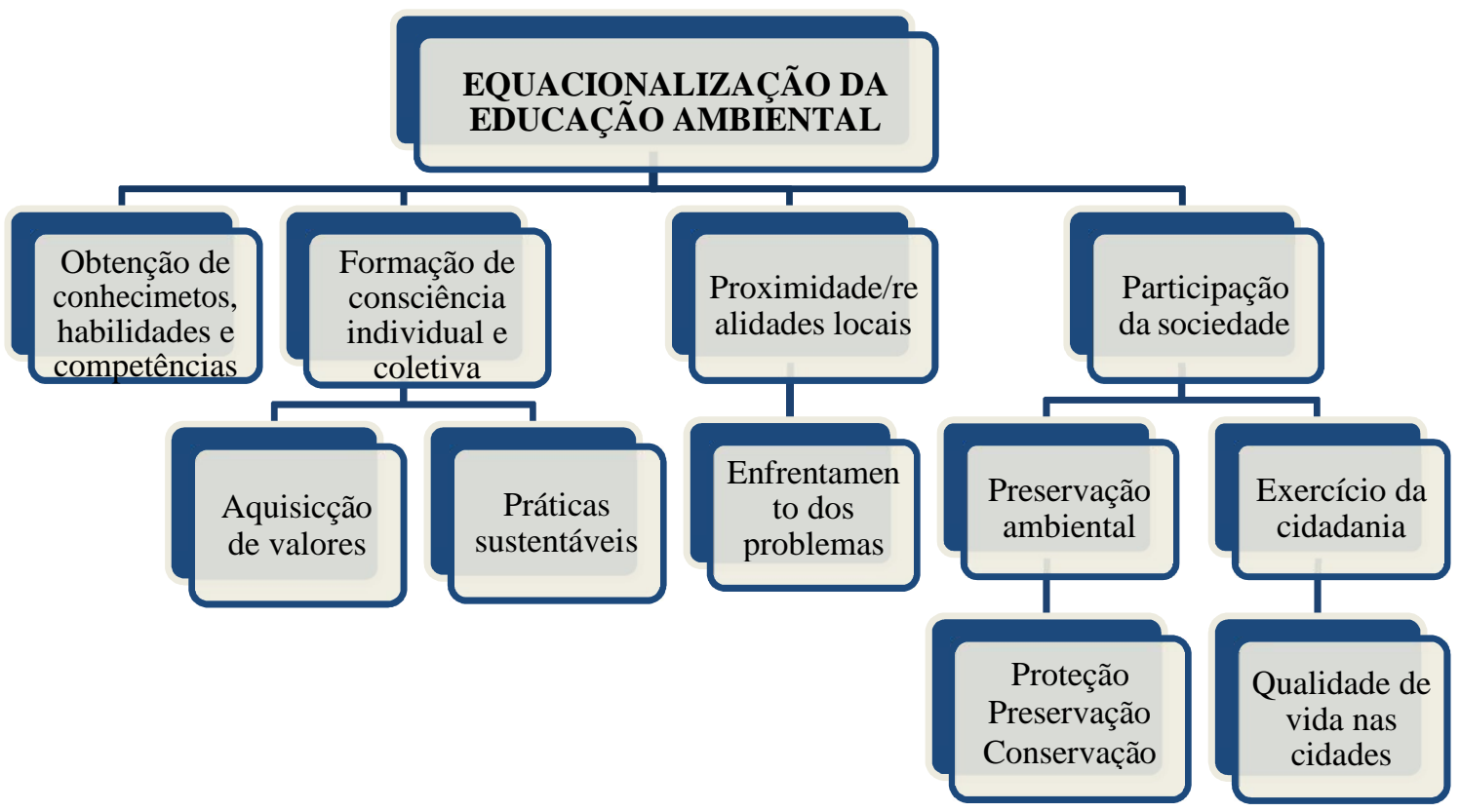

Organização e elaboração pela autora.

Desse modo, as práticas em educação ambiental não podem tratar os acontecimentos da realidade social de forma dissociada das experiências significativas dos atores sociais.

É preciso buscar alternativas para uma proposta ambiental inovadora, que busque aliar os diversos saberes, flexibilizar o currículo, dinamizar as metodologias e considerar as diversidades existentes no contexto local. É preciso criarmos os mecanismos necessários para formarmos cidadãos mais comprometidos com a sua comunidade e com o meio em que vive.

As formas de pensar, agir e de participação dos atores sociais na construção de novas possibilidades de atuação no meio ambiente através de práticas sustentáveis são essenciais no processo de conscientização pública acerca das problemáticas ambientais e a mola propulsora no desenvolvimento de uma sociedade mais justa e igualitária podendo promover mudanças significativas na sociedade e consequentemente nas cidades.

Convém ressaltar, que são necessários maiores investimentos, mais disponibilidade de recursos materiais para a execução de projetos de educação ambiental. É preciso um olhar mais comprometido por parte dos governantes para garantir uma estrutura mínima de qualidade.

A educação ambiental configura-se numa prática que não se realiza sozinha, mas nas relações com o ambiente, na interação entre diferentes atores, que leva os sujeitos a se 
perceberem, enquanto indivíduos, como um elo importante do sistema, participando ativamente de seu desenvolvimento.

Destarte, a educação ambiental proporciona que os indivíduos adquiram conhecimentos, valores, comportamentos e habilidades para participarem de forma responsável e eficaz na prevenção e solução dos problemas ambientais, e na gestão da qualidade do meio ambiente, transcendendo assim, os limites de uma prática, ainda comum, exclusivamente informativa das questões ambientais, para a melhor gestão dos recursos naturais, pressupondo o conhecimento crítico da dinâmica societária e da constituição da cidadania em um mundo cada vez mais globalizado.

Ela deve buscar valores que conduzam a uma convivência harmoniosa com o ambiente e as demais espécies que habitam o planeta, auxiliando o indivíduo a analisar criticamente as suas ações, que tem levado à destruição inconsequente dos recursos naturais e de várias espécies, sendo com isso importante a inclusão da educação ambiental na educação formal e informal. Haja vista, que o conceito moderno de educação ambiental defendido por Dias ${ }^{29}$ considera o meio ambiente em sua totalidade e dirige-se ás pessoas de todas as idades, dentro e fora da escola, de forma contínua, sintonizada com suas realidades sociais, econômicas, culturais, políticas e ecológicas, estimulando e orientando para o exercício pleno e responsável de cidadania.

Para alcançarmos um ambiente sustentável deve se admitir que as gerações futuras assim como as atuais precisam de qualidade de vida. Para isso é necessário uma sociedade mais justa que garanta a inclusão social com posturas e relações ambientais que indiquem a atuação de um sujeito realmente ético, no meio em que vive. Devendo assim investir em uma mudança de mentalidade, orientando os grupos humanos para a necessidade de se adotarem novos conceitos e novas posturas que permita a construção de um equilíbrio entre o homem e meio.

\section{CONSIDERAÇÕES FINAIS}

Os problemas ambientais causados pela ação do homem impõem a necessidade de se buscar formas de desenvolvimento adequado ao meio ambiente. É necessário uma maior

\footnotetext{
${ }^{29}$ DIAS, 2002.
} 
articulação das práticas existentes, pois somente assim é possível contribuir para a mudança desse contexto.

A convivência cotidiana deve permitir a participação de toda a comunidade na construção de ações ambientais mais concretas, de forma a estabelecer canais de conexão com a realidade local alcançando assim outras esferas sociais.

A educação ambiental desponta como um mecanismo de grande importância nesse processo. Pois por meio dela o indivíduo pode assumir um papel central, participando ativamente no diagnóstico dos problemas e na busca de soluções, sendo preparado como agente transformador através do desenvolvimento de habilidades e formação de atitudes, através de uma conduta ética, condizentes ao exercício da cidadania.

Desse modo, esta pesquisa vem indicar que a educação ambiental quando aplicada de forma correta pode ser uma grande aliada para podermos alcançar a sustentabilidade nas cidades. O compromisso de cada cidadão com a comunidade em que está inserido é fundamental para que este possa atuar como participante da sociedade, sabendo relacionar as ações sociais com a natureza de forma equilibrada, ética e justa.

As pequenas mudanças de comportamentos podem contribuir para a diminuição de agressões ao meio ambiente. Elas surgem como um processo educativo de formação da cidadania ecológica, que se refere a uma nova forma de encarar a relação do homem com a natureza, baseada numa nova ética, que pressupõe outros valores morais e uma forma diferente de ver o mundo e os homens através de um processo de conscientização para reverter ou pelo menos tentar reduzir os impactos que o homem vêm ocasionando ao meio ambiente.

As práticas sociais devem estarem sincronizadas com meio ambiente para garantir a sua preservação. Contudo, para que dê resultados é preciso que toda a sociedade colabore e participe da construção de uma mudança de mentalidade e consequentemente de hábitos em relação à problemática ambiental. Tal conscientização não se dá de um dia para outro, mas através de um trabalho constante de educação ambiental que garanta o envolvimento e a participação de todos.

Os governantes e os formuladores de políticas públicas podem ordenar mudanças e novos enfoques para a educação ambiental, primando pela instauração de novas e produtivas relações entre estudantes e professores, entre a escola e a comunidade, e consequentemente, entre o sistema educativo e a sociedade em geral. 
A educação ambiental desponta como um recurso na defesa do meio natural e ajudam a reaproximar o homem da natureza, garantindo um futuro com mais qualidade de vida para todos, já que tende a desperta nos indivíduos maior responsabilidade em relação ao ambiente em que vive.

É indispensável a busca pela sustentabilidade ambiental e para que isso se efetive é preciso da implementação de projetos e programas bem elaborados e eficazes, capazes de estabelecer fontes de recursos, associada a uma consistente política de conscientização de acordo com as especificidades locais, considerando as rápidas mudanças espaciais, políticas, sociais e econômicas, a fim de garantir um meio ambiente saudável com justiça social, equidade, combate à pobreza e a melhoria das condições de vida a todos os cidadãos.

Isto posto, nos leva à reflexão sobre a necessidade da formação de cidadãos mais conscientes, para desenvolver práticas mais harmoniosas em relação ao meio ambiente numa perspectiva crítica, que abra possibilidades para atuações sustentadas por princípios da responsabilidade ecológica e a capacidade de formular e desenvolver práticas emancipatórias norteadas pela justiça ambiental e social que repercuta na qualidade de vida das populações nas cidades.

Portanto, apesar dos entraves, contradições e desafios que precisam ser enfrentados permanentemente, acreditamos que as reflexões e contribuições deste trabalho podem abrir espaço para novas discussões e outras conexões em prol de novos projetos.

\section{REFERÊNCIAS BIBLIOGRÁFICAS}

BARROS, Marlene Pagliaroni Becker de. Aprendizagem ambiental: Uma abordagem para a sustentabilidade. 2002. 116p. Dissertação (Mestrado em Engenharia de Produção) - Programa de Pós-Graduação em Engenharia de Produção, Universidade Federal de Santa Catarina, Florianópolis, 2002.

BRASIL. Lei no 9.795, de 27 de abril de 1999. Dispõe sobre a educação ambiental, institui a Política Nacional de Educação Ambiental e dá outras providências. Diário Oficial da União, Brasília, DF, 28 de abril de 1999. Disponível em: < http://www.planalto.gov.br/ccivil_03/Leis/L9795.htm>. Acesso em: $24 / 01 / 2016$.

CARVALHO, G. A. Desenvolvimento, implementação e avaliação de um programa de educação ambiental a campo para escolas de 1ㅇ e 2ㅇ graus. Florianópolis, 2001. 131f. Universidade Federal de Santa Catarina. Disponível em:<http://teses.eps.ufsc.br>. Acesso em: 13 de agosto de 2017. 
CURRIE, Karen. L. Meio Ambiente: Interdisciplinaridade na Prática. 6 ed. São Paulo: Papirus Editora, 2005. 184p.

DIAS, Genebaldo Freire. Iniciação a Temática Ambiental. 2 ed. São Paulo: Global, 2002. 110p.

DIAS, Genebaldo Freire. Educação Ambiental: princípios e práticas. 9a ed. São Paulo: Gaia, 2004. $551 p$.

DUVOISIN, Ivane Almeida. A necessidade de uma visão sistêmica para a educação ambiental: conflitos entre o velho e o novo paradigmas. In: RUSCHEINSKY, Aloísio (org.). Educação Ambiental: abordagens múltiplas. Porto Alegre: Artmed, 2002. p. 91-103.

GIESTA, Nágila Caporlíngua. Histórias em quadrinhos: recursos da educação ambiental formal e informal. In: RUSCHEINSKY, Aloísio (org.). Educação Ambiental: abordagens múltiplas. Porto Alegre: Artmed, 2002. p. 157-167. 312p.

GONÇALVES, Rosângela Aparecida da Silva; LIMA, Rosely Maria de. Educação Ambiental no Ensino Fundamental: um caminho a ser percorrido em defesas das águas. In: ASARI, Alice Yatiyo; ANTONELLO, Ideni Terezinha; TSUKAMOTO, Ruth Youko. (Org.). Múltiplas Geografias: EnsinoPesquisa-Reflexão. Londrina: Humanidades, 2004. p. 245-259.

GRÜM, Mauro. Ética e educação ambiental: a conexão necessária. Campinas: Papirus, 1996. 126p.

HERMOSO, Mário. A contribuição da Educação Ambiental para a formação de pedagogos. 2005. 151p. Dissertação (Mestrado em Engenharia de Produção) - Programa de Pós-Graduação em Engenharia de Produção, Universidade Federal de Santa Catarina, Florianópolis, 2005.

LERÍPIO, Alexandre A. GAIA - um método de gerenciamento de aspectos e impactos ambientais. 2001. Tese (Doutorado em Engenharia da Produção) - Programa de Pós-graduação em Engenharia da Produção, Universidade Federal de Santa Catarina, Florianópolis, 2001.

LIMA, Cristiane Cavalcante; MOURÃO, Arminda Rachel Botelho. A representação social da educação ambiental: a visão docente no curso de Pedagogia. Manaus: Editora da Universidade Federal do Amazonas, 2007. 88p.

MEDINA, Naná Mininni; SANTOS, Elizabeth da Conceição. Educação Ambiental. 6ạ ed. Petrópolis, RJ: Vozes, 2009. 231p. 
RUSCHEINSKY, Aloísio; VARGAS, Sérgio Hiandui Nunes de. Agroecologia e reforma agrária: integração possível e necessária. In: RUSCHEINSKY, Aloísio (org.). Educação Ambiental: abordagens múltiplas. Porto Alegre: Artmed, 2002. p. 127-141.

RUSCHEINSKY, Aloísio. Atores socioambientais. In: FERRARO JÚNIOR, Luiz Antonio (org.). Encontros e caminhos: formação de educadoras (es) ambientais e coletivos educadores. Brasília: MMA, Departamento de Educação Ambiental: 2007. p. 23-34.

SANTOS, Maurício Takahashi dos. Consciência ambiental e mudanças de atitudes. 2005. 135p. Dissertação (Mestrado em Engenharia de Produção) - Programa de Pós-Graduação em Engenharia de Produção, Universidade Federal de Santa Catarina, Florianópolis, 2005.

VALDAMERI, Adelar José. Educação Ambiental: Um Diagnóstico em Escolas Municipais. 2004. 91p. Dissertação (Mestrado em Engenharia de Produção) - Programa de Pós Graduação em Engenharia de Produção, Universidade Federal de Santa Catarina, Florianópolis, 2004.

VIOLA, Eduardo; LEIS, Hector. A evolução das políticas ambientais no Brasil, 1971-1991: do bissetorialismo preservacionista para o multissetorialismo orientado para o desenvolvimento sustentável. In: HOGAN, D. J. \& VIEIRA, P. F (org.). Dilemas socioambientais e desenvolvimento sustentável. Campinas, SP: UNICAMP, 1995. p. 73-102.

WARREN, Ilse Scherer. Redes sociais e de movimentos. In: FERRARO JÚNIOR, Luiz Antonio (org.). Encontros e caminhos: formação de educadoras (es) ambientais e coletivos educadores. Brasília: MMA, Departamento de Educação Ambiental: 2007. p. 325- 332.

Trabalho enviado em 19 de abril de 2019

Aceito em $\mathbf{2 0}$ de abril de $\mathbf{2 0 2 0}$ 